\title{
SOME THOUGHTS ABOUT THE FUTURE
}

\author{
B. F. SKINNER
}

\section{HARVARD UNIVERSITY}

In The Shaping of a Behaviorist (1979) I wrote that in 1947 , looking back upon my research at Minnesota and Indiana, I saw that

there had been a change in emphasis in my experimental work. When Garry Boring wrote to Mike Elliott to support my appointment at Minnesota, he said that I had been "sheltered" by five years of research fellowships. I was only just beginning to see an important effect. Almost all the experiments reported in The Behavior of Organisms were done to follow up leads arising from the work itself. I answered questions, clarified points, and solved practical problems raised by my own research. Once out of my shelter and in contact with other people, I turned to other questions: at Minnesota, to how fast rats pressed at maximal hunger, whether maze-bright and maze-dull rats differed in extinction, whether a rat could use tokens, and what effect drugs had on behavior; and at Indiana, reaction time, choice, and matching to sample. These were a kind of technological application of the operant methodology. I was using an experimental analysis of behavior rather than furthering it. The results were interesting to many more people, but they were digressions. (p. 343)

At Harvard, in collaboration with Charles B. Ferster, I returned to basics, but schedules of reinforcement proved almost too fascinating, and what I should have called central issues only occasionally broke through. Recently, in a brief return to the laboratory I once again considered issues that came not from the research itself but from an application-to the simulation of so-called cognitive processes.

Our research on Project Pigeon during the Second World War was also a technological application of the operant analysis. My colleagues and I had to convince some very skeptical engineers that a living organism was at least as reliable as any other part of the missile they were working on. We did not convince the engineers, but we ourselves were more than satisfied with the control we achieved. One episode in particular made a great difference in later years. We discovered the ease with which we could shape the behavior of a pigeon simply by operating a reinforcing device with a hand switch at appropriate times.

I had been talking about control for many years, but now I began to do so in earnest. With a group of philosophers and literary critics I discussed many of the implications of a scientific analysis of human behavior. Much of Walden Two is little more than a rehash of those discussions. What the protagonist in Walden Two called a behavioral technology was at the time still science fiction, but it soon moved into the real world. Curiously enough, there does not seem to have been a comparable interest in total control in basic research.

\section{THE CONTROL OF BEHAVIOR}

In the 1930s I was asking whether the behavior of a rat was determined and, if so, to what extent it could be predicted and controlled in an experimental space. If we could control all relevant conditions, could we explain everything the rat did? Some kinds of exceptional behavior are familiar. Adjunctive behavior is an example, and so is the emotional display seen during extinction-defecation in the case of the rat, and defecation, pacing, cooing, and ruffling of feathers in the case of the pigeon. Another example is the pigeon's occasional peck at some other feature of the apparatus ("displacement"?). Not quite unrelated to the experiment is a sharp turning away from the key, evidently a kind of escape that can be studied directly by installing a second key that stops the experiment briefly when pecked. We accept a certain amount of this, although it must affect our results. Can we eliminate it? One way, possibly not intentional, is to make intervals of reinforcement so short or ratios so small that the pigeon responds very rapidly and has little time for anything else, but the steep, straight lines that 
appear in so many reports are uninteresting and have almost been the death of the cumulative record.

In the 1930s I studied low rates. Knowing far less about why an organism behaves than I do now, I was content to see a few signs of lawful behavior against a background of "noise." I was impressed by the fact that a rat wandered about the box, sniffed in corners, explored the ceiling, sat and scratched itself, and nevertheless went to the food tray and ate a pellet of food at just the right time to keep a satiation curve on its proper course. I gave exceptional behavior every chance and found a kind of order in spite of it. As we shall see, low rates of responding similar to those in most of The Behavior of Organisms (1938) may be essential if we are to observe certain complex interactions among the effects of controlling variables.

The experimental chamber and its use in operant research is a kind of "preparation," like Sherrington's for the study of spinal reflexes or Thomas Hunt Morgan's for the study of genetics. A species of organism is chosen and a standard space constructed. A corpus of facts about the organism is accumulated so that further research in a similar space need not start from scratch.

Certain features of the operant preparation are in danger of being lost. Much valuable research can be done in short periods of time on one or a few subjects. The experimenter can then watch the organism, observing features of its behavior that are lost by the time the data reach a recorder. Closed-circuit television makes it easy to watch behavior without disturbing the organism, and videotaping permits review and even the quantification of certain observed effects.

Pigeons are highly suitable for a good preparation. We have already learned a great deal about them. Their adequacy as a sample of organisms in general is a question, of course, but so is that of, say, a hundred species when there are so many millions. The kind of pigeon, however, raises a problem. The Kings and White Carneaux usually found in the laboratory are not ideal. They are raised for squab meat and bred for weight, quick growth, efficiency in feeding their young, and good health in crowded quarters. They have lived in undemanding environments for many generations and may even have been selected against keen vision, good motor skill, and quick learning. Homing pigeons have been selected by more demanding contingencies and may be better subjects.

I am not sure that we have not made something of a fetish of naive pigeons. There are experiments in which they are necessary, of course, but a pigeon kept in a cage after hatching may be like a feral child. Sophistication has its advantages, and there is something to be said for a pigeon that has been around a long time. Ferster and I kept an old pigeon to test new circuits, and it became a kind of war horse that could put a new set of contingencies through its paces very quickly. It is true that some schedules have long-lasting effects, but perhaps a new setting takes total control more quickly after exposure to many settings. After all, the human subjects used in psychological research are not naive, even though we often wish they were. When the question is simply whether a pigeon can exhibit a given pattern of behavior, sophistication is clearly preferable to naiveté.

We can improve our control by improving daily care. A bit more living space, a controlled day-and-night light cycle, the use of only one sex to avoid incipient mating and brooding, a careful selection of food and grit, proper manicuring of beak and toes-all these should make for more uniform results.

The experimental space can also be improved. We are concerned with the behavior of a pigeon facing a panel bearing operanda, stimuli, and dispensers of reinforcers. The rest of the space should be as free as possible of eliciting and releasing stimuli. A cylindrical space would be better than a square one because it would have no odd corners to be explored. If the wall were transparent, the pigeon could be watched, either directly or with a video camera, through an opening in a larger, sound-absorbing enclosure.

The keys, with the usual standard specifications, should be set at a convenient height, and if different sizes of pigeons are used, the height should be adjusted. The pigeon should be able to reach reinforcers and drinking water without moving away from the panel. Most of the time a pigeon stands facing the panel because standing there is indirectly reinforced by the reinforcers in the experiment, but it will be more likely to remain there if additional contingencies are arranged. A small area 
in front of the panel that is especially comfortable for pigeon feet would help. After all, we use special contingencies to keep our human subjects in their places. (Those who complain of the artificiality of animal research, by the way, often seem to forget that the psychological laboratory is also far from the natural environment of the human species.)

When I was a graduate student, experiments in animal behavior were conducted in open rooms with the experimenter present and watching. Taking my cue from Pavlov, I put my first lever and reinforcer in a fairly soundproof room and later in a fairly sound-proof box, but I worried about the effect of handling. In my first experiments, I put the rat first into a special section of the box, from which I released it (electrically and silently) after it had presumably recovered from being handled. Something of the sort should, I think, be standard practice. A sophisticated pigeon may not need time to recover from handling, but a naive one certainly does. With pigeons, the space can be kept dark for a time. With animals that are active in the dark, the operandum and panel can be covered for a minute or two before the experiment starts.

Contingencies of reinforcement should be programmed with standard equipment, of course, and in many experiments the behavior is still most usefully recorded in cumulative records, which are especially useful when rates are low and curves are curved. Measures of interresponse times and on-line computer processing also have their place, of course.

Circadian rhythms are important, and if we are to achieve anything like total control, they should be respected. Experiments should start at the same time every day in a 7-day week. That is not a feature of a preparation that appeals to everyone, but it is probably needed if we are to gain accurate control. Young workers may be willing to accept them, as I did, for the sake of the advantages.

The experiments described below can be carried out with a relatively simple preparation. They resemble, but go far beyond, the experiments I reported in The Behavior of Organisms (1938). It is the kind of research in which something new and interesting turns up almost every day. In other words, the experimenter's behavior is reinforced on a rich variable-ratio schedule.

Research of this kind also has economic ad- vantages. It is much less expensive than research designed to test theories or to confirm principles. Budgets are getting smaller, and grants are always hard to get when agencies demand a clearer picture of potential results than is possible in truly exploratory research. Of course, one may try to impress granting agencies by giving one's work a broader significance. For example, most of what I shall describe could be called either the study of cognitive processes or, to use Pavlov's expression, "an investigation of the physiological activity of the cerebral cortex." There is always the danger, however, that a move in that direction will lead to digressions.

Cooperation with workers in other fields is often a useful source of support, however. We sometimes forget how far we have come as skilled craftsmen who can shape and maintain behavior to specification. When we speak of applied behavior analysis we usually mean applied to human behavior in the world at large, but research with operant equipment and methods in neurological and pharmacological laboratories is also applied and is often closer to basic research.

Here are some fields of operant research that I would be looking at closely if I were to return to the laboratory.

\section{Choice}

An organism is said to choose when it responds in a way that makes it impossible for another response to occur. All early animal research used choice-of pathways in mazes or of doors in discrimination boxes and jumping stands-as a measure of strength of response. Edward Tolman used a $T$ maze to study "behavior at a choice point." But the fact that a rat turns right rather than left or jumps to a circle rather than a square shows only that one response is stronger than another; it does not show by how much stronger or yield an absolute measure of strength. Rate of responding comes much closer.

As I reported in The Shaping of a Behaviorist (1979), when Tolman read The Behavior of Organisms, he wrote that I ought to put two levers in the box and "see what relationships the functions obtained from such a discrimination set-up will bear to your purified functions where you have only one lever" (p. 312); and when W. T. Heron and I built our 24box Behemoth, I wrote to Tolman that we 
had put in two levers and hoped to get around soon to some problems involving choice. Fortunately, we never made that mistake.

To return to choice and especially to regard a single response as a choice between responding and not responding are, I think, steps backward. Choice is something to be explained, not to be used in the analysis of basic processes. Its recent use in animal research may have been encouraged by similar treatments of human behavior. For the utilitarians, a choice was right if it promoted the greatest good for the greatest number; economists have appealed to the maximization of utility, as in the theory of subjective expected utility; and behavioral scientists speak of the optimization or melioration of other consequences.

Choice is needed only when there is no other measure of probability of responding. It is true that if a man does not do one thing, he will do another or do nothing, and that if you want him to do $A$ and not $B$, you have only to make the "expected utility" of A greater than that of $B$ as by describing favorable consequences or reinforcing A more frequently. But you are changing only relative probabilities. Contingencies of reinforcement are much more powerful than the "expected utilities" that follow from instruction, and rate of responding is a more direct measure of probability than a choice between alternatives.

I reported some work on "behavior at a choice point" in "Are Theories of Learning Necessary?" (1950), in which by occasionally reinforcing a response on one or the other of two keys without favoring either key, I obtained equal rates of responding. "The behavior approaches a simple alternation from one key to the other. This follows the rule that tendencies to respond eventually correspond to the probabilities of reinforcement." That was an early statement of the matching law, but I hastened to add that

the bird's behavior does not correspond to this probability merely out of respect for mathematics. The specific result of such a contingency of reinforcement is that changing-to-the-other-key-and-striking is more often reinforced that striking-the-same-keya-second-time. [I was using an interval schedule.] We are no longer dealing with just two responses. In order to analyze "choice" we must consider a single final re- sponse, striking, without respect to the position ... of the key, and in addition the response of changing from one key ... to the other. (p. 211)

It is unlikely that a remote consequence of any kind can reinforce operant behavior in the absence of mediating events. When a schedule is suddenly changed so that the current rate of responding does not match the frequency of reinforcement, the behavior does not immediately change. Mediating processes must be conditioned before the new performance matches, and the conditioning is presumably the same as that which explains all schedule effects. It is also unlikely that remote consequences could have played any part in the evolution of the process of operant conditioning.

To return to choice after better measures of strength are available is like returning to the gas laws for information about the behavior of molecules after better ways of observing them have been discovered. The gas laws remain valid and useful, and so would laws about more general effects of contingencies if they could be proved.

\section{Stimulus Control}

We shall not achieve total contol of operant behavior until we know more about the role of stimuli. Very early in my research I found it necessary to distinguish between what I called the discriminative stimulus in an operant and the eliciting stimulus in a reflex. I had been reinforcing a rat's behavior every 5 min, and when I began to turn on a light just as I set up a reinforcement, and off again immediately after a response, responding persisted in the presence of the light but disappeared in extinction in its absence. The term "discrimination," which I took from contemporary work on animal behavior, was not quite right. I did not really care whether a rat could tell the difference between light-on and lightoff. The control acquired by a stimulus was the issue. I began to speak of a stimulus as "the occasion" for a response or even of responding "in" a stimulus as short for "in the presence of," but neither expression quite represents the way in which a stimulus gains control of an operant.

A related process that most people were calling generalization I called induction. Re- 
inforcement "in light-on" generated some tendency to respond "in light-off." On Project Pigeon we found that in extinction after intermittent reinforcement of pecking a red triangle, the rate dropped when the triangle turned yellow. Guttman's work on stimulus generalization was, of course, a great clarification of that effect. Much more could be done to explore its relevance to "our knowledge of the world around us."

I tried to study induction by setting up a discrimination between two stimuli in one of which behavior had never been reinforced. As I reported it in The Behavior of Organisms (1938):

At the release of the rat on the first day the light was on. A response to the lever occurred quickly and was reinforced. The light and magazine were then disconnected.... Only two responses were forthcoming during the next five minutes and it is difficult to say whether they show induction or are similar to [that is, occurred for the same reason as] the first response. When the light was turned on again, the rat responded after 39 seconds. ... Both light and magazine were then turned off, and two more responses in the dark occurred during the next five minutes. (pp. 203-205)

During the rest of the session there were only two or three small groups of responses in the dark, and I noted that some of them could have been due to adventitious reinforcement by the appearance of the light.

Herbert Terrace took off from that experiment in his work on errorless discrimination learning. By building an easy errorless discrimination between very different stimuli and then superimposing very similar stimuli on them and vanishing the originals, he taught his pigeons to distinguish between very similar stimuli without error. That a discrimination learned without errors produced no peak shift in the generalization gradient suggests that other riches lie unexplored in that field.

Another process that I called reverse induction still puzzles me. Two of the eight rats in my experiment soon stopped responding altogether in the light as well as the dark although responses were always reinforced in the light. In a third rat "inductive extinction nearly brought the series to an end in the last part of the second [period]" (1938, pp. 206207). A rat would often wait nearly a minute before responding. The average latency during $6 \mathrm{hr}$ was $41 \mathrm{~s}$. The average for all six rats was roughly three times that in my earlier experiments on discrimination. So far as I know, reverse induction has never been studied further, although it might throw unexpected light on "cognitive" processes and on puzzling problems in therapy.

\section{Reaction Time}

Early in the history of psychology, reaction time was taken as an important measure of the speed of mental processes, and cognitive psychologists are again using it as such. Differences in reaction times have even been said to reflect differences in intelligence, but if that is the case, it is surprising that, as I found many years ago, the reaction time for the pigeon is probably within the human range when the contingencies are properly programmed. Reaction times are only secondary properties of behavior, possibly of value when we are guessing about what is going on inside the organism, but otherwise of interest only because complex cases are a challenge to the programmer of contingencies.

In the simplest case, a "ready" signal is given and after a short variable time a key is lighted and a response is reinforced if it occurs within a given period, eventually to be measured in milliseconds. Initially a length of period is chosen in which reinforcement frequently occurs. The period is then progressively shortened as the pigeon responds more and more quickly. Responses made during the ready period turn the experiment off for a few seconds. Good waiting behavior eventually develops, but it can be quickly shaped if we end the ready period whenever the pigeon looks steadily at the key. When human subjects are told to "behave as fast as possible," the instruction presumably works because of similar contingencies in the subject's history, largely unknown to the experimenter. Because we must construct the pigeon's history, we know much more about it and, indeed, about the role of reaction times in daily life.

Reaction-time experiments could occupy a researcher for a lifetime. How do the times differ when a response is reinforced only if 
the key is red and not if it is green, or when either a right or a left key is lighted, or when both keys are lighted but reinforcement is contingent on pecking the one that matches a color present during the ready period, or when a tone is used instead of a light. And so on, and on. Skillful programming is needed, but that is what the experimental analysis of behavior is all about.

\section{Multiple Operants}

In one of the experiments I look back on with particular pleasure, William $\mathrm{H}$. Morse and I used both water and food as reinforcers. There were three keys. Responses on one were intermittently reinforced with water, on another with food, and on the third with food or water unpredictably. The result was beautiful. As we changed the levels of deprivation of food and water, the rates on the respective keys changed, and the rate on the key to which responses were reinforced with food or water was always the average of the other two. A simple result but one that has vast implications for the field of "motivation."

An equally fascinating question is whether a pigeon can engage in more than one operant performance at the same time. Suppose we light the left of two keys and build a steady low rate of pecking. In a separate session we build a somewhat higher rate on the lighted right key, keeping the left key dark. Eventually, in a single session, the pigeon responds at a low rate whenever the left key is lighted and at a higher rate when the right key is lighted. On the critical day, both keys are lighted and the same schedules are in effect but with reinforcements out of phase. The time needed to consume the reinforcers should be negligible, and the two performances should run off essentially undisturbed. If there is any disruption, it will be what is right for the pigeon and what the experimenter must explain. In an interesting variation, responses on the left key could be reinforced with food and those on the right with water.

On Project Pigeon, Norman Guttman began an experiment in which a jacketed pigeon pecked a key but also pulled a string with one free leg. He could not finish the experiment before he was called to his country's service. Something of the sort badly needs to be explored. An unjacketed pigeon might either peck a key or step on a treadle. Bring each response under appropriate stimulus control and then present both stimuli at the same time. The extent to which two or more operants can appear as parts of ongoing behavior without loss of stimulus control or confusion in topography is an extremely important question if we are ever to give a plausible account of behavior in the world at large.

\section{Schedules of Reinforcement}

If Ferster and I had had another year or two to work together, we might have brought the analysis of schedules of reinforcement to a more satisfying state-though by no means to a conclusion. As I reported in A Matter of Consequences (1983),

we had a theory. Unless our pigeons had extrasensory perception (a suggestion we dismissed), their only contact with the programming equipment came at the moment of reinforcement. But a number of stimuli were acting at that moment corresponding to readings on a speedometer (the bird had been responding at a given rate), a clock (a certain amount of time had passed since the last reinforcement ...), and a counter (a given number of responses had been made since the last reinforcement). We designed our experiments to give these stimuli a chance to make their presence known. (pp. 73-74)

One of our more surprising results came when we added counters, clocks, and speedometers to the keys the pigeons pecked. The instrumentation was crude. We projected a small bar of light on the key, the length of which changed with the number of pecks, elapsed time, or speed. We assumed that the bar and the internal stimulus changed in the same way, but it was soon clear that in general the bar was much stronger. So far as I know, this work has never been followed up, yet it could throw a great deal of light on why schedules have their appropriate effects. It would be an alternative to current work in which much more elaborate contingencies of reinforcement can be programmed with an on-line computer.

\section{Bonuses}

As more control is achieved, other kinds of variables can be brought into an experiment at little or no extra cost. Bonuses are there for 
the asking. A few examples: (1) If we use two strains of pigeons (of both sexes), and if significant differences in their behavior appear, we can cross-breed and see what happens. (2) If we can arrange for the care of pigeons, we can put our subjects aside at the end of an experiment and bring them back a few years later to test for long-term remembering. (3) We can study the effects of diet far beyond anything possible with human subjects; vitamin deficiencies could be a starting point. (4) We can study visual processes in the pigeon with great precision, and there are diets and drugs that change the pigments in the pigeon's eye-another experimental manipulation that is out of reach of research on human subjects.

\section{CONCLUSION}

It is much easier to suggest experiments than to carry them out, and it is tempting to claim a discovery simply for having said that it could be made, but I am not staking claims. I am simply trying to recover the spirit of the re- search reported in The Behavior of Organisms. I think the experimental analysis of behavior can best proceed as it started, until the control of the behavior of an organism in an experimental space is very nearly total. A science of behavior will then have given neurology its clearest assignment, will have left nothing for cognitive science to explain with its mental operations, and will lead most rapidly to an effective technology of behavior in the world at large.

\section{REFERENCES}

Skinner, B. F. (1938). The behavior of organisms. New York: Appleton-Century.

Skinner, B. F. (1948). Walden two. New York: Macmillan.

Skinner, B. F. (1950). Are theories of learning necessary? Psychological Review, 57, 193-216. (Reprinted in Cumulative record, 1959, 1961, 1972 [New York: Appleton-Century-Crofts].)

Skinner, B. F. (1979). The shaping of a behaviorist. New York: Knopf.

Skinner, B. F. (1983). A matter of consequences. New York: Knopf. 